\title{
Characterization of texture attributes of raw almond using a trained sensory panel
}

\author{
Loreto Contador $^{1}$, Bárbara Robles ${ }^{1}$, Paulina Shinya ${ }^{1}$, Marcela Medel ${ }^{2}$, Catalina Pinto $^{1}$, Gabino Reginato ${ }^{1}$ \\ and Rodrigo Infante ${ }^{1 \star}$ \\ 1 Departamento de Producción Agrícola, Universidad de Chile, Santiago 8820808, Chile \\ 2 Departamento de Agroindustria y Enología, Universidad de Chile, Santiago 8820808, Chile
}

Received 28 April 2014 - Accepted 31 March 2015

\begin{abstract}
Introduction. Texture parameters are important factors for characterizing the sensory quality of raw almonds; nevertheless there is scarce literature that explores sensory differences among cultivars. The aim of this study was to characterize quality attributes of different raw almond cultivars. Materials and methods. The almond cultivars 'Nonpareil', 'Mission', 'Supernova', 'Tuono', 'Ferragnès' and 'Marcona' were used to characterize their industrial and sensory quality attributes. A panel of 14 assessors with previous experience in testing stone fruit was specifically trained on descriptive analysis for determining quality and particularly texture of raw almonds. Results and discussion. A direct relationship was observed between kernel yield and shell fracture resistance; the American cultivars 'Nonpareil', and 'Mission' showed more minor shell fracture resistance than the European. 'Tuono' stood out for being tasty, crunchy and hard, whereas 'Marcona' was noted for its color intensity, crispness and hardness; but it lacked taste. 'Supernova' was described as tasty. Conclusion. A 5-h training period proved to be adequate for characterizing raw almond cultivars. The panel was able to discriminate between cultivars and segregate 'Nonpareil' and 'Mission' from the other cultivars in terms of texture attributes.
\end{abstract}

Keywords: Chile / almond / Prunus dulcis / sensory analysis / texture / food quality

\begin{abstract}
Résumé - Caractérisation des attributs de texture de l'amande crue par un panel sensoriel entraîné. Introduction. Les paramètres de texture doivent être pris en compte pour caractériser la qualité sensorielle de l'amande crue; pourtant la littérature qui explore les différences sensorielles entre cultivars est rare. Le but de cette étude est de caractériser les attributs de qualité de différents cultivars d'amande crue. Matériel et méthodes. Les cultivars d'amandier 'Nonpareil', 'Mission', 'Supernova', 'Tuono', 'Ferragnès' et 'Marcona' ont été utilisés pour caractériser les attributs de qualité industrielle et sensorielle de leurs fruits. Un panel de 14 experts ayant une expérience des tests sur fruits à noyau a été formé spécifiquement sur l'analyse descriptive pour déterminer la qualité, et en particulier la texture de l'amande crue. Résultats et discussion. Une relation directe a été observée entre le rendement en noyaux d'amande et la résistance de la coque à la fracture ; les cv. américains 'Nonpareil' et 'Mission' ont montré une moindre résistance de la coque que les cv. Européens. 'Tuono' s'est distingué pour être savoureux, croustillant et dur, tandis que 'Marcona' a été noté pour l'intensité de sa couleur, le croquant de l'amande et la dureté de la coque; mais il manque de goût. 'Supernova' a été décrit comme savoureux. Conclusion. Une période de formation de $5 \mathrm{~h}$ s'est révélée être suffisante au panel pour caractériser les amandes crues de plusieurs cultivars d'amandiers. Le panel a été capable de discriminer les cultivars et de distinguer 'Nonpareil' et 'Mission' des autres cultivars en termes d'attributs de texture.
\end{abstract}

Mots clés : Chili / amandier / amande / Prunus dulcis / analyse sensorielle / texture / qualité du produit

\section{Introduction}

Global almond production has grown since the mid-1990s as a result of the change in consumption patterns towards healthy foods [1]. Almond (Prunus dulcis syn. P. amygdalus)

\footnotetext{
^ Corresponding author: rinfante@uchile.cl
}

is a high-value food due to the high content of numerous beneficial nutritional and bioactive compounds [1]. These compounds are vitamin E, arginine, oleic and linoleic acid, fiber and other micronutrients and phytochemical compounds associated with the prevention of heart-related diseases, cancer [2], type II diabetes and obesity, and also these compounds exhibit anti-aging effects $[3,4]$. 
There are two types of almonds according to markets: hard-shelled and soft-shelled. The former type is more characteristic of the Mediterranean countries while the latter have been bred and cultivated in California. Almonds are consumed toasted or raw. Toasting is an ancient practice aimed at making the flavor richer and the aroma more complex so the resulting product is more appreciated by consumers. The toasting process is also used for the production of a much crunchier almond [5]. However, almonds as a raw product are also available in the market even though there is less research on its sensory quality in general and its texture in particular [6]. The sensory properties of almonds are desirable on their own, their characteristic flavor and also as an added flavor when mixed with other foods. In regard to texture; hardness and crunchiness are almond's most salient sensory attributes [7].

The sensory variability of raw almond cultivars and within the same cultivar has neither been intensely studied nor understood [7]. Sensory differences have been reported in terms of appearance, aroma, flavor and texture on almonds of various origins, but these differences have not been quantified [8]. The sensory characteristic of other nut species such as peanuts has been properly described; furthermore on almond, the descriptive analysis has been focused almost exclusively on the roasted product $[7,9]$.

Descriptive analysis is a valuable tool used to characterize the sensory properties of foods allowing different cultivars of fresh fruit to be compared. Civille et al. [7] developed a lexicon to assess almond's sensory properties. A lexicon corresponds to a comprehensive vocabulary developed by a descriptive panel, which are specifically trained for evaluating a food. For developing a lexicon a reference list that contains different products must be collected and evaluated by the panel. This list must consider the widest range of flavors, aromas and textures [7]. Sensory analysis needs a group of trained assessors, which must use an agreed vocabulary. In order to have a reliable panel, intensive training is required; however, to overcome this constraint the Free Choice Profiling procedure was developed [8]. This procedure allows the assessors to use their own vocabulary without being trained in the use of specific descriptors. In the case of raw almonds, the Free Choice Profiling with semi-trained assessors reduced the main problems associated with the definition of descriptors and produced descriptors which were simple and easy to understand [8].

The most relevant parameters that define almond quality are those associated with texture. In fact, the combination of acoustic recording with mechanical tests resulted in a more reliable and objective way of analyzing the sound emissions and allowed the study of different parameters by correlating them with sensory traits $[9,10]$. The integration of the energy dissipation with the analysis of sound emission has been shown to be crucial for understanding almond crispness and crunchiness. It has been demonstrated that crispness is highly correlated with the rate of sound emission and with the size of acoustic peaks emitted during chewing [5].

The objective of this paper was to evaluate some industrial quality features of five almond cultivars and assess texture attributes of raw almond of six cultivars through descriptive analysis.

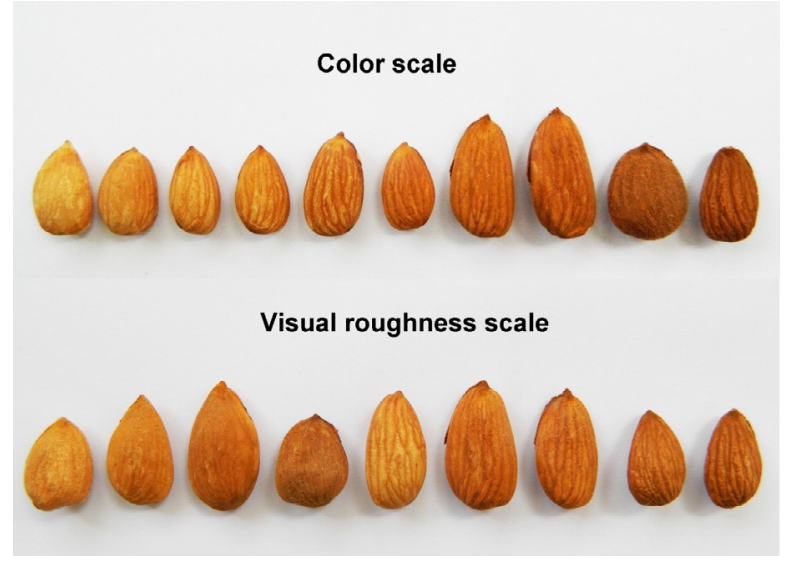

Figure 1. The sensory attributes "visual roughness" and "colour intensity" from lower to higher intensity, from left to right for raw almond (Prunus dulcis).

\section{Materials and methods}

Almond (Prunus dulcis (Mill.) syn. P. amygdalus Batsch) fruits were harvested from the germplasm bank belonging to the University of Chile, Santiago, Chile ( $33^{\circ} 34^{\prime} 02 \mathrm{~S} ; 70^{\circ} 38^{\prime}$ $23 \mathrm{O}$ ), and the postharvest evaluations were performed at the Fruit Quality \& Breeding Laboratory. For the evaluation of industrial quality the cultivars used were 'Nonpareil', 'Mission', 'Supernova', 'Tuono', and 'Ferragnès'. Harvest was executed manually when $95 \%$ of hulls were split. Immediately afterwards fruits were completely hulled and left to dry in open air for 7 days. In the performance of the sensory evaluation trial the cultivar 'Marcona' was also included.

\subsection{Fruit characterization}

The ratio between the mass of the kernel $(\mathrm{g})$ and fruit whole mass (g) (shelling percentage) was calculated in a sample of 50 fruits per cultivar; the results were expressed as $(\mathrm{w} / \mathrm{w})$ percentage. The resistance of the shell to rupture by compression (shell resistance) was evaluated in three samples per cultivar. Each sample was placed horizontally between two parallel plaques, and compression was applied until the shell ruptured. An Instron Universal Testing Machine (Instron, High Wycombe, U.K.) with a load cell of 5,000 N was used.

Training of the panel for descriptive analysis [8]: A group of 14 panelists, aged 21-35 years (6 men and 8 women) with broad experience in sensory evaluation of fresh peach, apricot and plum were selected and trained following the ISO standard 8586-1 [12].

Qualitative stage: The "visual roughness", the "color intensity" (figure 1), the "flavor intensity", the "crunchiness", the "crispness" and the "hardness" were chosen as the descriptors that best defined the quality of a raw almond. On table I, these attributes are defined and the evaluation technique used for assessing each one is indicated.

Quantitative stage: During the training phase a consensus was achieved regarding the definition and meaning of the chosen attribute terms and their evaluation protocols. An intensity 
Table I. Attributes used for raw almond sensory evaluation and definition of the evaluation technique employed for assessing each one.

\begin{tabular}{lll}
\hline Attribute & Definition & Technique \\
\hline Visual roughness & $\begin{array}{l}\text { Number of hills and valleys visible } \\
\text { on the surface of the sample }\end{array}$ & $\begin{array}{l}\text { Visual assessment, depending on how many } \\
\text { hills and valleys there are in the kernel }\end{array}$ \\
\hline Color intensity & $\begin{array}{l}\text { Intensity or strength of color } \\
\text { from light to dark }\end{array}$ & $\begin{array}{l}\text { Visual assessment of the surface } \\
\text { of the kernel }\end{array}$ \\
\hline Intensity of flavor & $\begin{array}{l}\text { Intensity of flavor of the almond } \\
\text { Crispness }\end{array}$ & $\begin{array}{l}\text { Putting two whole almonds at } \\
\text { once in the mouth and chew }\end{array}$ \\
& $\begin{array}{l}\text { Sound events that are perceived strong, fast and sharp, } \\
\text { evaluated with the incisors and lips open }\end{array}$ & $\begin{array}{l}\text { Putting the almonds between the incisors, } \\
\text { bite and evaluate the sound intensity after } \\
\text { the first bite }\end{array}$ \\
\hline Crunchiness & $\begin{array}{l}\text { Multiple low-pitched sounds, perceived as a series of small } \\
\text { events, evaluated with molars and closed lips }\end{array}$ & $\begin{array}{l}\text { Putting the almonds between molars and chew } \\
\text { 2-3 times, sound intensity will be heard }\end{array}$ \\
\hline Hardness & $\begin{array}{l}\text { Force required compressing completely a sample } \\
\text { between the molars. Measuring the resistance of a product } \\
\text { to deformation or rupture }\end{array}$ & $\begin{array}{l}\text { Putting the almonds between the molars, bite and } \\
\text { assess the force required to compress the sample }\end{array}$ \\
\hline
\end{tabular}

scale for each attribute was developed in which samples ought to be correctly ranked by each panelist according to a ranking method [13]. This phase of the training process is aimed at improving the ability of the assessors to recognize different intensities and therefore to develop the capability to establish a hierarchy for a given attribute. This method consists on the ranking of several randomly provided samples from the least intensity ( -$)$ to the greatest (+) intensity.

For attributes "crispness" and "crunchiness", the scale used was (-) walnut : cashew : peanut : pistachio : almond : hazelnut : Japanese peanut (+); and for the attribute "hardness" the scale was: $(-)$ cashew : walnut : peanut : pistachio : hazelnut : almond (+). For the visual attributes "roughness" and "color intensity" each assessor chose from a sample of at least five almonds those that represented the levels of each attribute. The individual results were compared with a previously defined scale, in which the criteria used and the ends of the scales were established. In order to generate the scale of "flavor intensity", a commercial brand of almond flavor concentrate (Good Food S.A., Santiago, Chile) was used $(60 \mathrm{~mL})$ at different product concentrations diluted in water: $(-)$ pure water, $0.5,0.6,0.8$, $1.0,1.2$ or $1.4 \mathrm{~mL} \mathrm{~L}^{-1}(+)$. The final part of the training phase included an evaluation session where all the almond cultivars were tasted. The sample was formed by 10 almonds, which were provided in a $100 \mathrm{~mL}$ glass vessel. The evaluation scale was an unstructured $15-\mathrm{cm}$ long line the ends of which were related to the sensory extremes of each attribute.

\subsection{Sensory analysis}

The sensory evaluation was performed in individual booths and following the protocols of UNE 87-004-79 [14]. Samples were presented in a random order to each assessor, and were associated to a three-digit code. First, 'Nonpareil', 'Supernova' and 'Ferragnès' were evaluated and 30 minutes later 'Tuono', 'Mission' and 'Marcona'. The evaluation guidelines considered a continuous scale for each attribute, ranging from 0 to 15 .

\subsection{Statistical analysis}

Concerning the evaluation of panel training, and in order to assess the discrimination capacity of each panelist, the inversion number was calculated by using the subtraction (in absolute value) between the correct rank of the sample (according to its intensity) and the position where it was placed by the assessor, and then the obtained value of each remainder was added. The inversion number of each assessor must be equal to, or less than $n+1$ ( $n=$ the number of samples) for being considered having discriminating capacity [15].

Likewise, the analytical ability of the sensory panel as a single entity had to be corroborated. The inversion number of the panel as a whole was calculated by taking the total sum of the partial values of each sample performed by the whole panel. Then, this total sum was multiplied by the correct rank position of each sample within the series. These values were added, and the total inversion number of the panel was obtained by Page's test [15]. If the inversion number of the panel (Ha) was higher than the table number (Ho), it was considered that the panel significantly discriminates the difference between samples [16].

Characterization of the fruit: Correlation and regression analyses were performed, using as dependent variables the mass of the kernel, productivity and kernel yield and as independent variables the mass of the almond and the shell's resistance.

Sensory quality of the kernel: The results were analyzed by ANOVA [17], and means were separated by Fisher's LSD multiple range test, $P<0.05$, when significant differences were detected. A principal components analysis (PCA) and hierarchical clustering were used to find homogenous groups. In all cases the statistical program InfoStat version 2013 was used [18].

\section{Results and discussion}

\subsection{Characterization of the nut}

The cultivar 'Nonpareil' showed the lowest mass while on the contrary 'Ferragnès' showed the highest mass reaching 


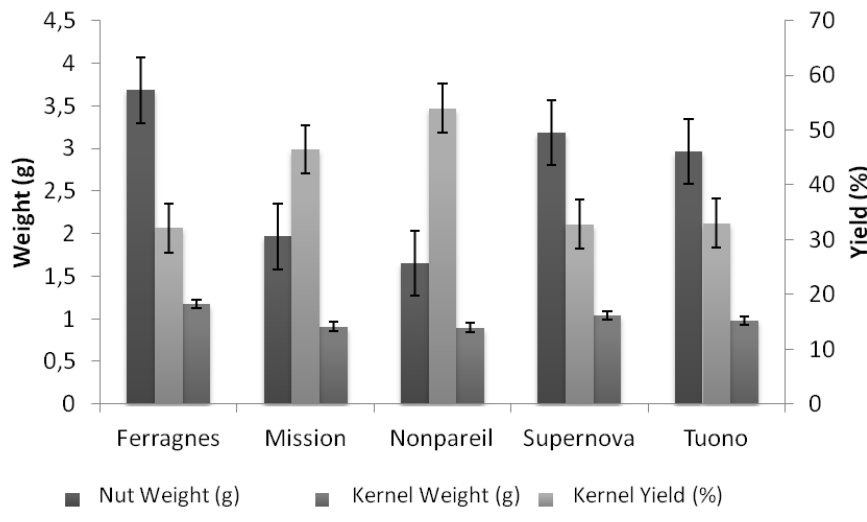

Figure 2. Raw almond in-shell nut and kernel mass, and kernel yield expressed as percentage. Standard error is shown for each parameter $(n=50)$.

values near $5 \mathrm{~g}$ per kernel. The ratio of masses is reflected in the kernel yield in terms of total mass that is directly related to shell hardness. The characterization of the almond and its kernel are of great importance for the classification of the product $[7,9]$. In fact, the physical properties, such as the kernel mass, the shape, the color and the texture are parameters of great interest to the industry $[7,9,19]$, because some commercial and logistical aspects, such as toasting, are affected by them.

The hardness of the shell has a great importance for the industry, and soft-shelled cultivars generally reach higher kernel yield $[19,20]$. The cultivar 'Nonpareil' showed the highest kernel yield, reaching 54\% (figure 2) due to its thin shell, followed by 'Mission' with $46 \%$. There were no differences in kernel yield $(\approx 30 \%)$ between 'Ferragnès', 'Supernova' and 'Tuono', and all of them can be classified as hard-shelled cultivars. The almond's shell is considered as a sub-product of the industry; it has numerous use possibilities, as heavy metal adsorbent and as culture substrate, or as a source of antioxidants [21]. Therefore, analyzing the mechanical properties of the shell will determine the best industrial potential of each genotype. The relationship between the kernel yield and the resistance of the shell is a well-known fact and has been reported before [22]. The American cultivars 'Nonpareil' and 'Mission' showed higher yield associated with less resistance of the shell, i.e. $400 \mathrm{~N}$ to achieve the shell's rupture. On the other hand, the European cultivars showed a resistance of the shell greater than $600 \mathrm{~N}$, and in the case of 'Supernova' almost $1,000 \mathrm{~N}$. The comparison of 'Nonpareil' with a hard-shelled Turkish cultivar showed rheological differences between them, and it was concluded that the industrial processing should be different per each cultivar [23].

\subsection{Panel training}

Descriptive analysis is an extremely useful tool to determine differences and to characterize food products objectively [17]. Therefore, for evaluating different fruit, and particularly for nut species, trained sensory panels have been employed for pistachio [24]; walnut [25]; and chestnut [26].
Table II. Inversion number of the panelists for each attribute assessed on raw almond and inversion number of the panel ( $\mathrm{Ha}$ ) compared to the computed number (Ho) for each one. Level of significance $(P=0.05)$ is indicated $(*)$.

\begin{tabular}{lcccc}
\hline Panelist & $\begin{array}{c}\text { Flavor } \\
\text { intensity }\end{array}$ & Crispness & Crunchiness & Hardness \\
\hline $\mathrm{A}$ & 2 & 4 & 2 & 4 \\
$\mathrm{~B}$ & 4 & 6 & 2 & 6 \\
$\mathrm{C}$ & 6 & 4 & 0 & 6 \\
$\mathrm{D}$ & 4 & 6 & 6 & 2 \\
$\mathrm{E}$ & 10 & 4 & 4 & 6 \\
$\mathrm{~F}$ & 4 & 0 & 2 & 6 \\
$\mathrm{G}$ & 10 & 2 & 2 & 8 \\
$\mathrm{H}$ & 8 & 8 & 2 & 6 \\
$\mathrm{I}$ & 4 & 0 & 2 & 6 \\
$\mathrm{~J}$ & 6 & 4 & 4 & 4 \\
$\mathrm{~K}$ & 10 & 6 & 2 & 10 \\
$\mathrm{~L}$ & 6 & 4 & 6 & 6 \\
$\mathrm{M}$ & 6 & 6 & 2 & 6 \\
$\mathrm{~N}$ & 6 & 6 & 6 & 5 \\
\hline Number of samples & 7 & 7 & 7 & 6 \\
Ha & 1.595 & 1.914 & 1.934 & 1.200 \\
Ho & $1.295^{*}$ & $1.639^{*}$ & $1.639^{*}$ & $928^{*}$ \\
\hline
\end{tabular}

Choosing to use the texture attributes to define the quality of the almond has been used on other nut species before, as the attributes 'hardness' and 'crispness' on pecan [27]; 'firmness' on chestnut [28]; and 'crispness' on almond [29] and cashew nut [30]. The attributes "crispness" and "crunchiness" are terms that refer to the sound that occurs when chewing a food [31], and are associated to materials that are essentially non-deformable therefore are broken with relative easiness [31]. This characteristic is consistent with the nature of most nut species. The release of energy during the rupture of the nut produces the characteristic sound when it is bitten and chewed.

All the assessors exhibited a good understanding of the concepts and adequate preparation for facing the scales for the attributes "crispness" and "crunchiness"; and all of them have been able to discriminate the samples correctly (table II). Nevertheless, two of them did not reach the required threshold for the attribute "hardness" and three of them did not reach the threshold for "intensity of flavor" (table II). In these cases those assessors that obtained the minimum inversion numbers, i.e. who did not discriminate the samples correctly were eliminated for data analysis. As far as the discrimination of the panel as a whole is concerned, it was able to correctly discriminate attributes "crispness", "crunchiness", "hardness" and "intensity of flavor" (table II). Most sensory panel training programs aimed to perform descriptive analysis require up to $120 \mathrm{~h}$ of training [32]. However, training periods of $4 \mathrm{~h}, 60 \mathrm{~h}$ or $120 \mathrm{~h}$ employed for testing fresh tomato paste showed no significant differences, and even with the 4-h training period the panelists detected differences between products [33]. On this investigation, training people with previous experience on stone fruit species shows that the 5-h period has been sufficient for constituting a panel that was able to discriminate texture properties between different almond cultivars. 
Table III. Sensory attributes of 'Nonpareil', 'Mission', 'Supernova', 'Tuono', 'Ferragnès' and 'Marcona' raw almond. The evaluation guidelines considered a continuous scale for each attribute, ranging from 0 (lowest score) to 15 (highest score).

\begin{tabular}{|c|c|c|c|c|c|c|c|c|c|c|c|c|}
\hline \multirow{3}{*}{$\frac{\text { Cultivar }}{\text { 'Nonpareil' }}$} & \multicolumn{12}{|c|}{ Attribute } \\
\hline & \multicolumn{2}{|c|}{ Color intensity } & \multicolumn{2}{|c|}{ Roughness } & \multicolumn{2}{|c|}{ Favor intensity } & \multicolumn{2}{|c|}{ Crispness } & \multicolumn{2}{|c|}{ Crunchiness } & \multicolumn{2}{|c|}{ Hardness } \\
\hline & 6.9 & $\mathrm{~d}^{*}$ & 11.4 & $\mathrm{~b}$ & 9.8 & $a b$ & 9.7 & $a b c$ & 7.6 & $\mathrm{ab}$ & 8.1 & $\mathrm{c}$ \\
\hline 'Supernova' & 9.7 & $\mathrm{bc}$ & 2.6 & $\mathrm{~d}$ & 11.0 & $\mathrm{a}$ & 9.3 & $\mathrm{ac}$ & 9.6 & $a b$ & 10.2 & $a b c$ \\
\hline 'Ferragnès' & 8.6 & $\mathrm{~cd}$ & 10.4 & $\mathrm{~b}$ & 9.3 & $a b$ & 11.1 & $a b c$ & 9.9 & $a b$ & 11.1 & $a b$ \\
\hline 'Tuono' & 7.5 & $\mathrm{~cd}$ & 4.9 & $\mathrm{c}$ & 11.5 & $\mathrm{a}$ & 11.5 & $a b$ & 10.7 & $\mathrm{a}$ & 12.2 & $\mathrm{a}$ \\
\hline 'Marcona' & 13.4 & $\mathrm{a}$ & 5.4 & $\mathrm{c}$ & 7.0 & $\mathrm{~b}$ & 12.2 & $\mathrm{a}$ & 10.4 & $a b$ & 11.7 & $\mathrm{a}$ \\
\hline 'Mission' & 11.7 & $\mathrm{ab}$ & 14.1 & $\mathrm{a}$ & 9.2 & $\mathrm{ab}$ & 8.4 & $\mathrm{c}$ & 7.2 & $\mathrm{~b}$ & 8.3 & $\mathrm{bc}$ \\
\hline
\end{tabular}

*Different letters indicate significant differences $(P \leq 0.05)$ between cultivars; Fisher's LSD test.

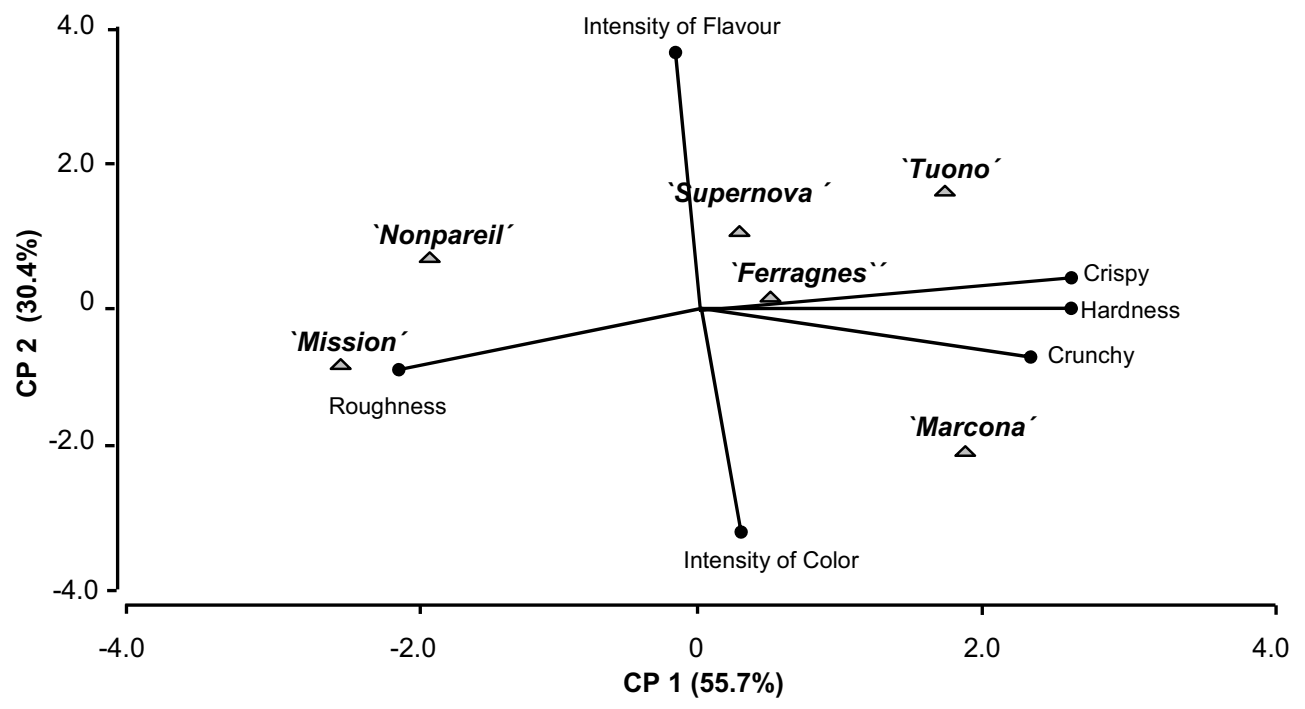

Figure 3. Principal components analysis for sensory attributes of six raw almond cultivars.

\subsection{Sensory quality of the fruit}

The genetic background of the almond is a factor that has an impact on the perception of its sensory characteristics that also influence the final quality of the fruit. The effect of the cultivar on the perception of quality has also been observed in pistachio [24]. In this experiment there were significant differences among cultivars $(P \leqslant 0.05)$, which are shown on table III. It was observed that 'Marcona' presented the highest "color intensity" and 'Nonpareil' the lowest one. The cultivar 'Mission' presented the highest "visual roughness" and 'Supernova' the lowest one. For the attribute "flavor intensity", cultivars 'Supernova' and 'Tuono' stand out as the tastiest cultivars. This result could be explained because they are genetically almost indistinguishable, since 'Supernova' might be originated from a mutation of 'Tuono' (or 'FascionelloRome'), inheriting its self-compatibility, which is a highly appreciated trait, currently exploited for breeding purposes [11]. In fact 'Supernova' is a self-fertile cultivar that might be derived from 'Fascionello-Rome' because they share the same microsatellite (SSR) patterns. However the cultivar 'Fascionello' from Sicily does not have the Sf allele, and it differs at several SSR loci from 'Fascionello-Rome' and from 'Supernova'. Surprisingly, 'Fascionello-Rome' and 'Supernova' have the same fingerprint as 'Tuono', which is a cultivar from the Apuglia region, instead than from Sicily. Therefore, 'Fascionello-Rome' is considered actually the same as 'Tuono' [11].

It was observed that also the taste was similar for both genotypes. Concerning the texture attributes, 'Marcona' proved to be the crispiest, and 'Tuono' the crunchiest, and both were shown to have the highest "hardness". As a result, the sensory quality of 'Tuono' stood out as being a tasty, crunchy and hard almond. 'Marcona' was noted for its color intensity, crispness and hardness; however this cultivar lacks taste. The cultivar 'Supernova' was described as a tasty almond. Cultivars 'Nonpareil' and 'Mission' were characterized by a high "visual roughness", an attribute that relates to texture and an irregular surface, which is detrimental to the appearance of the fruit [7]. At the same time, these cultivars reached low scores in the other attributes, the overall sensory quality being rather mediocre.

The PCA explained $86 \%$ of the total variation of the model (figure 3). The PC1 explained $56 \%$ of the total variation, which is associated to texture and to the attribute "visual roughness". Cultivars 'Mission' and 'Nonpareil' were associated with "visual roughness", and they were opposed to attributes "crunchiness", "hardness" and "crispness". 'Marcona' was associated with "color intensity" and to "crispness". 'Supernova' and 'Tuono' on the other 


\section{Average linkage \\ Distance: (Euclidea)}

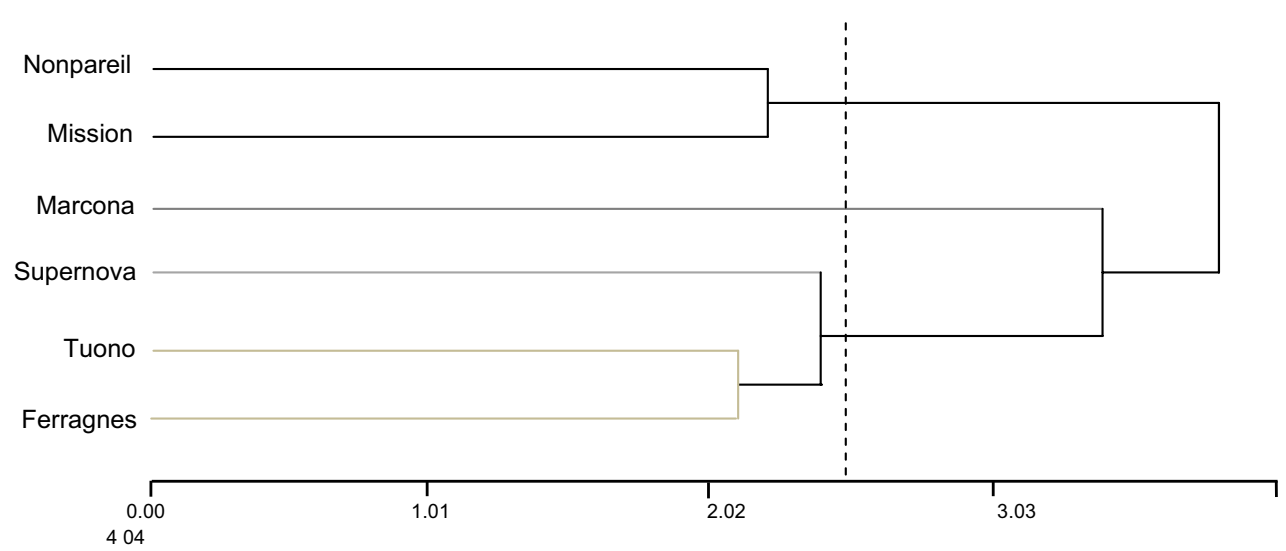

Figure 4. Cluster analysis of six cultivars of raw almond based on sensory characteristics (reference line at a distance of $75 \%$ from the maximum distance).

hand, were associated with "flavor intensity", "crunchiness" and "hardness". The correlations between the quality attributes "Crunchiness"-"Hardness", "Crispness"-"Hardness" and "Crispness"-"Crunchiness", reached values $r=0.98$, 0.86 and 0.83 , respectively. These texture parameters are correlated positively among them, and as observed before similar results were reached on the correlation "hardness" and "crunchiness" on biscuits (0.84) [34]. This positive correlation between "hardness" and "crispness" and "crunchiness" is explained because these attributes are intimately related to the fracture properties of food. When the initial fracture occurs, i.e. when the food is broken, this phenomenon spreads thereby creating a series of new fracture surfaces [35]. Although a consensus has not yet been reached on an exact definition of the attributes "crispness" and "crunchiness", it is quite clear that both are related to the fracture properties of food [31]. Therefore, these attributes tend to be correlated positively because from a sensory perspective they are perceived mainly by the sense of hearing [36]. Specifically the almond, when compared as a raw product to almonds with different toasting levels, it was observed that when toast level was higher the number of sounds peaks during chewing increased as well [5]. This result might be due to the fact that on those much more toasted almonds there was less free water, thus less water activity [10].

Cluster analysis shows that the first group comprised the American cultivars 'Mission' and 'Nonpareil', forming a cluster that was differentiated from the other cultivars (figure 4). The Spanish cultivar 'Marcona' was perceived with a higher color intensity, which separated it from the other European cultivars. The almond kernel quality is a quite important issue; however, they are often superseding yield considerations in determining commercial acceptance. In Spain and almost in all the world, 'Marcona' is considered the almond with the best sensory quality, and it fetches higher prices than other cultivars, but shows important production problems as frost damage induced by its early blooming, and pollination deficiencies due to its self-incompatibility, which is critical under bad weather conditions during blooming [19]. The cultivar
'Nonpareil' dominates commercial production in California; primarily because it combines a good market quality with good yields [19]. The challenge for the next years will be to develop new Cultivars that could exhibit the highest sensory quality traits coupled with the high productivity potential of North American cultivars.

\section{Conclusion}

The American Cultivars 'Mission' and 'Nonpareil' proved to have lower shell fracture resistance and greater kernel yield compared with the other cultivars. It has been possible to develop a reliable sensory panel for raw almonds with a brief training session of $5 \mathrm{~h}$, constituted by assessors previously trained on other stone fruits. The panel was able to discriminate among the six tested cultivars, and identify the 'Supernova' and 'Tuono' as the tastiest genotypes, and the latter as the crunchiest. In addition, cultivars 'Mission' and 'Nonpareil' were clearly differentiated from the European cultivars 'Marcona', 'Supernova', 'Tuono' and 'Ferragnès', forming independent groups in terms of sensory attributes.

Acknowledgements. This research was conducted with the funding from CONICYT through the scholarship "Doctorado Nacional 2010" awarded to LC (Doctorado en Ciencias Silvoagropecuarias y Veterinarias, Universidad de Chile), and by funding of FONDECYT project \#1130198.

\section{References}

[1] Chen C.Y., Lapsley K., Blumberg J., A nutrition and health perspective on almonds, J. Sci. Food Agric. 86 (2006) 2245-2250.

[2] Sabate J., Ang Y., Nuts and health outcomes: new epidemiologic evidence, Am. J. Clin. Nutr. 89 (2009) S1643-S1648.

[3] Wijeratne S.S.K., Abou-Zaid M.M., Shahidi F., Antioxidant polyphenols in almond and its coproducts, J. Agric. Food Chem. 54 (2006) 312-318. 
[4] Garrido I., Monagas M., Gomez-Cordoves C., Bartolome B., Polyphenols and antioxidant properties of almond skins: Influence of industrial processing, J. Food Sci. 73 (2008) C106-C115.

[5] Varela P., Chen J., Fiszman S., Povey M.J.W., Crispness assessment of roasted almonds by an integrated approach to texture description: texture, acoustics, sensory and structure, J. Chemom. 20 (2006) 311-320.

[6] Varela P., Salvador A., Fiszman S., On the assessment of fracture in brittle foods II. Biting or chewing? Food Res. Int. 42 (2009) 1468-1472.

[7] Civille G.V., Lapsley K., Huang G., Yada S., Seltsam, J., Development of an almond lexicon to assess the sensory properties of almond varieties, J. Sens. Stud. 25 (2010) 146-162.

[8] Jack F.R., Piggott J.R., Free choice profiling in consumer research, Food Qual. Prefer. 3 (1991) 129-134.

[9] Guerrero L., Gou P., Arnau J., Descriptive analysis of toasted almonds: a comparison between expert and semi-trained assessors, J. Sens. Stud. 12 (1997) 39-54.

[10] Chauvin M.A., Younce F., Ross C., Swanson B., Standard scales for crispness, crackliness and crunchiness in dry and wet foods: Relationship with acoustical determinations, J. Texture Stud. 39 (2008) 345-368.

[11] Marchese A., Boskovic R.I., Martinez-Garcia P.J., Tobutt K.R., The origin of the self-compatible almond 'Supernova', Plant Breed. 127 (2008) 105-107.

[12] ISO, ISO 8586-1: Sensory analysis-general guidance for the selection, training and monitoring of assessors, ISO 85861, Geneva: International Organization for Standardization, Geneva, 1993.

[13] Labuza T.P., Schmidl M.K., Use of sensory data in the shelf-life testing of foods - principles and graphical methods for evaluation, Cereal Foods World 33 (1988) 193-206.

[14] A.A.E.d.N., UNE 87-004-79. Análisis sensorial. Guía para la instalación de una sala de cata, Norma Española, Madrid, España, 1979.

[15] Page E.B., Ordered Hypotheses for Multiple Treatments: A Significance Test for Linear Ranks, J. Am. Stat. Assoc. 58 (1963) 216-230.

[16] AENOR, UNE 87:023:1995 Análisis sensorial. Guía para la selección, entrenamiento y control de jueces, Norma Española, Madrid, España, 1995.

[17] Valentin D., Chollet S., Lelievre M., Abdi, H., Quick and dirty but still pretty good: a review of new descriptive methods in food science, Int. J. Food Sci. Technol. 47 (2012) 1563-1578.

[18] Infostat. (2013) http://www.infostat.com.ar/

[19] Socias i Company R.S.I., Kodad O., Alonso J.M., Gradziel T.M., Almond quality: A breeding perspective, Horticultural Reviews, John Wiley \& Sons, Inc., 2008.

[20] Verdu A., Vazquez-Araujo L., Miquel A., Martinez-Sanchez F., Carbonell-Barachina A.A., Discriminant analysis of almond cultivars used in turron, Ital. J. Food Sci. 22 (2010) 76-82.

[21] Esfahlan A.J., Jamei R., Esfahlan R.J., The importance of almond (Prunus amygdalus L.) and its by-products, Food Chem. 120 (2010) 349-360.
[22] Ledbetter C.A., Shell cracking strength in almond (Prunus dulcis Mill. DA Webb.) and its implication in uses as a value-added product, Bioresour. Technol. 99 (2008) 5567-5573.

[23] Aktas T., Polat R., Atay U., Comparison of mechanical properties of some selected almond cultivars with hard and soft shell under compression loading, J. Food Process Eng. 30 (2007) 773-789.

[24] Tsantili E., Takidelli C., Christopoulos M.V., Lambrinea E., Rouskas D., Roussos P.A., Physical, compositional and sensory differences in nuts among pistachio (Pistachia vera $\mathrm{L}$.) varieties, Sci. Hortic. 125 (2010) 562-568.

[25] Sinesio F., Moneta E., Sensory evaluation of walnut fruit, Food Qual. Prefer. 8 (1997) 35-43.

[26] Kunsch U., Scharer H., Patrian B., Hohn E., Conedera M., Sassella A., Jermini M., Jelmini G., Effects of roasting on chemical composition and quality of different chestnut (Castanea sativa Mill) varieties, J. Sci. Food Agric. 81 (2001) 1106-1112.

[27] Ocon A., Anzaldua Morales A., Quintero A., Gastelum G., Texture of pecans measured by sensory and instrumental means, J. Food Sci. 60 (1995) 1333-1336.

[28] Warmund M.R., Elmore J.R., Adhikari K., McGraw S., Descriptive sensory analysis and free sugar contents of chestnut cultivars grown in North America, J. Sci. Food Agric. 91 (2011) 1940-1945.

[29] Mexis S.F., Riganakos K.A., Kontominas M.G., Effect of irradiation, active and modified atmosphere packaging, container oxygen barrier and storage conditions on the physicochemical and sensory properties of raw unpeeled almond kernels (Prunus dulcis), J. Sci. Food Agric. 91 (2011) 634-649.

[30] Mexis S.F., Kontominas M.G., Effect of $\gamma$-irradiation on the physicochemical and sensory properties of cashew nuts (Anacardium occidentale L.), LWT - Food Sci. Technol. 42 (2009) 1501-1507.

[31] Luyten A., Pluter J.J., van Vliet T., Crispy/crunchy crusts of cellular solid foods: A literature review with discussion, J. Texture Stud. 35 (2004) 445-492.

[32] Meilgaard M., Sensory evaluation techniques, Taylor \& Francis, New York, 1999.

[33] Chambers D.H., Allison A.M.A., Chambers E., Training effects on performance of descriptive panelists, J. Sens. Stud. 19 (2004) 486-499.

[34] Brown W.E., Langley K.R., Braxton D., Insight into consumers' assessments of biscuit texture based on mastication analysis hardness versus crunchiness, J. Texture Stud. 29 (1998) 481-497.

[35] Kim E.H.J., Corrigan V.K., Wilson A.J., Waters I.R., Hedderley D.I., Morgenstern M.P., Fundamental fracture properties associated with sensory hardness of brittle solid foods, J. Texture Stud. 43 (2012) 49-62.

[36] De Belie N., Harker F.R., De Baerdemaeker J., Crispness judgement of royal gala apples based on chewing sounds, Biosyst. Eng. 81 (2002) 297-303. 